\title{
DEVELOPMENT OF THE MONTHLY AVERAGE DAILY SOLAR RADIATION MAP USING A-CBR, FEM, AND KRIGING METHOD
}

\author{
Choongwan $\mathrm{KOO}^{\mathrm{a}}$, Taehoon $\mathrm{HONG}^{\mathrm{b}}$, Kwangbok JEONG ${ }^{\mathrm{b}}$, Jimin $\mathrm{KIM}^{\mathrm{b}}$ \\ ${ }^{a}$ Department of Building Services Engineering, Faculty of Construction and Environment, \\ The Hong Kong Polytechnic University, Hong Kong \\ ${ }^{b}$ Department of Architectural Engineering, Yonsei University, Seoul, 03722, Republic of Korea
}

Received 27 April 2015; accepted 16 February 2016

\begin{abstract}
Photovoltaic (PV) system could be implemented to mitigate global warming and lack of energy. To maximize its effectiveness, the monthly average daily solar radiation (MADSR) should be accurately estimated, and then an accurate MADSR map could be developed for final decisionmakers. However, there is a limitation in improving the accuracy of the MADSR map due to the lack of weather stations. This is because it is too expensive to measure the actual MADSR data using the remote sensors in all the sites where the PV system would be installed. Thus, this study aimed to develop the MADSR map with improved estimation accuracy using the advanced case-based reasoning (A-CBR), finite element method (FEM), and kriging method. This study was conducted in four steps: (i) data collection; (ii) estimation of the MADSR data in the 54 unmeasured locations using the A-CBR model; (iii) estimation of the MADSR data in the 89 unmeasured locations using the FEM model; and (iv) development of the MADSR map using the kriging method. Compared to the previous MADSR map, the proposed MADSR map was determined to be improved in terms of its estimation accuracy and classification level.
\end{abstract}

Keywords: monthly average daily solar radiation, solar radiation map, advanced case-based reasoning, finite element method, kriging method.

JEL classification: C45, C52, C61, C63, D81, E27, Q01, Q21, R47.

Online supplementary material: Supporting information for this paper is available as online supplementary material at https://doi.org/10.3846/20294913.2016.1213198

\section{Introduction}

It is necessary to urgently solve the global warming and lack of energy due to excessive use of fossil fuels. The energy and environmental issues has been highlighted after the Fukushima Daiichi nuclear accident in March 2011 and the blackout in South Korea in September 2011 (Holt et al. 2012; Hong et al. 2014a, 2014b; Koo et al. 2014a). Accordingly,

Corresponding author Taehoon Hong

E-mail: hong7@yonsei.ac.kr 
the South Korean government has established the 4th Renewable Energy Penetration Plan, and also plans to expand the use of new and renewable energy (NRE) in the primary energy consumption from $4.33 \%$ (as of 2015) to 11\% (as of 2030) (KEMC 2012). It is expected that the proportion of the solar energy source to the total NRE supply would increase from $2.7 \%$ (as of 2015) to $4.1 \%$ (as of 2030). The solar energy source has a high potential, and it is considered to be suitable for buildings (Hong et al. 2014c; Lee et al. 2014a; Lueken et al. 2012).

Various factors should be considered to maximize the effectiveness of photovoltaic (PV) system. In particular, the monthly average daily solar radiation (MADSR) data should be collected to accurately estimate the amount of electricity generation from the PV system (Ashhab 2008; Badescu 1999; Cano et al. 1986; Chegaar, Chibani 2001; Coskun et al. 2001; Gastli, Charabi 2010; Geraldi et al. 2012; Hammer et al. 2003; Hong et al. 2013; Koo et al. 2014b; Reddy, Ranjan 2003). However, it is too expensive to measure the actual MADSR data using the remote sensors in all the sites where the PV system would be installed. To solve this problem, previous studies used various methodologies to estimate the MADSR data in the unmeasured locations (Al-Alawi, Al-Hinai 1998; Alsamamra et al. 2009; Behrang et al. 2010; Caglayan et al. 2014; Cogliani et al. 2008; Janjai 2010; Mohandes et al. 1998; Mubiru, Banda 2008; Ramedani et al. 2014; Saffaripour et al. 2013; Şahin et al. 2013; Sözen et al. 2005; Śúri, Hofierka 2004). Such methodologies could be categorized in three ways: (i) artificial intelligence technique; (ii) geostatistical technique; and (iii) satellite retrieval technique.

- (i) Artificial intelligence technique: Behrang et al. (2010) developed the estimation model for the daily global solar radiation on a horizontal surface using multi-layer perceptron (MLP) and radial basis function (RBF) neural network models. It was determined that the MLP model (mean absolute percentage error (MAPE): 5.21\%) was superior to the RBF model (MAPE: 5.56\%). Ramedani et al. (2014) developed several support vector regression (SVR) models to estimate global solar radiation. The SVR model (which was combined with RBF as a kernel function) was found to be superior to the SVR model (which was combined with the polynomial function, adaptive network-based fuzzy inference system, and artificial neural network (ANN)) in terms of the estimation accuracy. Şahin et al. (2013) developed the estimation model for solar radiation in Turkey using the MLP neural network model and the multiple linear regression (MLR) model. The MLP model was found to be superior to the MLR morel in terms of the root mean squared error, mean bias error, and coefficient of determination $\left(\mathrm{R}^{2}\right)$.

- (ii) Geostatistical technique: Alsamamra et al. (2009) estimated the monthly mean of global solar radiation in southern Spain using the ordinary and residual kriging methods. The residual kriging model was found to be superior to the ordinary kriging model in southern Spain. Caglayan et al. (2014) conducted a spatial viability analysis to determine the optimal grid-connected PV system with six power capacities $(0.2$, $0.5,1,3,5$, and $10 \mathrm{MW}$ ) in Turkey. To do this, the universal kriging method was used to estimate the mean annual global solar radiation, sunshine duration, and ambient air temperature. 
- (iii) Satellite retrieval technique: Cogliani et al. (2008) estimated the MADSR data in Italy using the "SOLARMET" model that was developed based on satellite data. Finally, the MADSR map was developed using the hourly MADSR data from the "SOLARMET" model. Janjai (2010) estimated the MADSR data in Thailand using the satellite-based diffuse fraction model that was developed based on "MTSAT-1R" satellite data. The root-mean-square deviation and the mean bias were determined to be $16 \%$ and $1.6 \%$, respectively.

As mentioned above, various previous studies were conducted to improve the estimation accuracy of the MADSR data in the unmeasured locations. However, there were several limitations as follows. (i) when the MADSR data were used to develop the MADSR map, it was determined to improve the estimation accuracy of the MADSR map and its classification level. However, previous studies used the only measured MADSR data in developing the MADSR map; and (ii) previous studies used the only one research technique (i.e., an artificial intelligence technique, a geostatistical technique, or a satellite retrieval technique). However, the estimation accuracy of the MADSR map and its classification level could be improved by combining the advantages of the several research techniques.

To address these challenges, some previous studies simultaneously used several research techniques to estimate the MADSR data in the unmeasured locations and to develop an MADSR map. Koo et al. (2013) estimated the MADSR data in the unmeasured locations using the advanced case-based reasoning (A-CBR) model that could be developed by combining the basic CBR, multiple regression analysis (MRA), ANN, and the genetic algorithm (GA). Lee et al. (2014a) proposed the framework for developing the MADSR map using the A-CBR model and kriging method. According to the studies of Koo et al. (2013) and Lee et al. (2014a), it is required to collect both the meteorological data from weather stations (e.g., the monthly average temperature, monthly average relative humidity, etc.) and the geographic data (e.g., the latitude and longitude, etc.), which were used to estimate the MADSR data in the unmeasured locations using the A-CBR model. However, due to the lack of weather stations, there was a limitation in the collection of the meteorological data. To fill the gap, this study used not only the A-CBR model to estimate the MADSR data in the unmeasured locations but also the finite element method (FEM) based on the meteorological and geographic data. In addition, based on the estimated MADSR data, this study developed more accurate MADSR map without the collection of the additional meteorological data.

\section{Materials and methods}

This study developed an MADSR map with improved estimation accuracy using the ACBR, FEM, and kriging method. Figure 1 shows the research framework in four steps: (i) step 1: data collection; (ii) step 2: estimation of the MADSR data in the 54 unmeasured locations using the A-CBR model; (iii) step 3: estimation of the MADSR data in the 89 unmeasured locations using the FEM model; and (iv) step 4: development of the MADSR map using the kriging method. In addition, this study conducted the validation for South Korea to verify the feasibility of the proposed MADAR map, which could allow potential readers to easily and clearly understand the MADSR estimation process. 


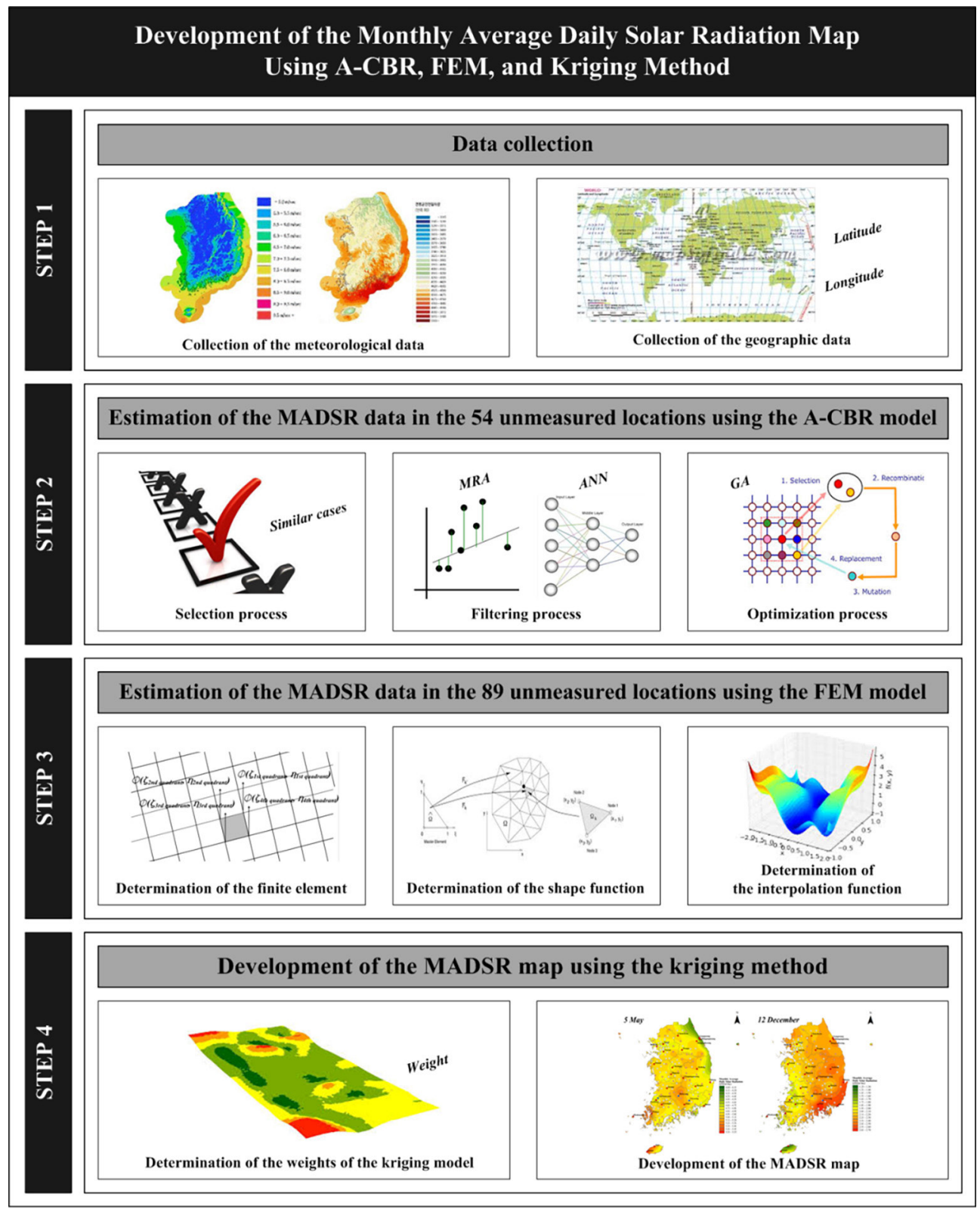

Fig. 1. Research framework

\subsection{Step 1: Data collection}

This study used the A-CBR, FEM, and kriging method to develop the MADSR map with improved estimation accuracy as follows: (i) the A-CBR model was used to estimate the MADSR data at the unmeasured locations using the meteorological data; (ii) the FEM model was used to estimate the MADSR data at the unmeasured locations using the geo- 
graphic data; and (iii) the kriging method was used to develop the MADSR map. To do this, it is necessary to collect the meteorological data including the MADSR data from weather stations and the corresponding geographic data (refer to Table 1 and Fig. 2).

- (i) Geographic data as the independent variable: This study collected the geographic data from the 167 locations of the regional representative cities in South Korea. Among the 167 locations, the 24 locations refer to the 24 weather stations where the MADSR data were measured (refer to the red circle in Fig. 3), the 54 locations refer to the 54 nodes hat were used as the independent variable in developing the A-CBR model (refer to the orange circle in Fig. 3), and the other 89 locations refer to the 89 nodes that were used as the independent variable in developing the FEM model (refer to the white circle in Fig. 3). This study collected several geographic data such as the longitude, latitude, and altitude (refer to Supplementary information, SI Table S1 and SI Table S2).

- (ii) Meteorological data as the independent variable: This study collected the meteorological data from the 78 weather stations in South Korea for eight years (2004-2011). Among the 78 locations, the 24 locations refer to the 24 weather stations where the MADSR data were measured (refer to the red circle in Fig. 3) and the 54 locations refer to the 54 nodes that were used as the independent variable in developing the A-CBR model (refer to the orange circle in Fig. 3). This study collected several meteorological data such as the monthly average temperature, monthly average relative humidity, monthly total sunshine duration, monthly average percentage of sunshine, precipitation, and monthly average wind speed.

- (iii) MADSR data as the dependent variable: This study collected the measured MADSR data from the 24 weather stations in South Korea for eight years (2004-2011), which were used as the dependent variable in developing the A-CBR model. As it is too expensive to measure the actual MADSR data using the remote sensors, the actual MADSR data could not be measured in all the sites but in the limited locations of the 24 weather stations in South Korea (refer to the red circle in Fig. 3 and SI Table S3).

Table 1. Dependent variable and independent variables affecting the MADSR

\begin{tabular}{|c|c|c|c|}
\hline Variables & & Attributes & Unit \\
\hline \multirow{9}{*}{$\begin{array}{l}\text { Independent } \\
\text { variable }\end{array}$} & \multirow{3}{*}{$\begin{array}{l}\text { Geographic } \\
\text { data }\end{array}$} & $\mathrm{X}_{1} \quad$ Longitude & ()$^{\circ} \mathrm{E}$ \\
\hline & & $\mathrm{X}_{2} \quad$ Latitude & ()$^{\circ} \mathrm{N}$ \\
\hline & & $\mathrm{X}_{3} \quad$ Altitude & ( ) $\mathrm{m}$ \\
\hline & \multirow{6}{*}{$\begin{array}{l}\text { Meteorological } \\
\text { data }\end{array}$} & $\mathrm{X}_{4} \quad$ Monthly average temperature & ()$^{\circ} \mathrm{C}$ \\
\hline & & $\mathrm{X}_{5}$ Monthly average relative humidity & ( ) $\%$ \\
\hline & & $\mathrm{X}_{6}$ Monthly total sunshine duration & ( ) hour \\
\hline & & $\mathrm{X}_{7} \quad$ Monthly average percentage of sunshine & ( ) $\%$ \\
\hline & & $\mathrm{X}_{8} \quad$ Precipitation & ( ) $\mathrm{mm}$ \\
\hline & & $\mathrm{X}_{9} \quad$ Monthly average wind speed & $(\mathrm{)} \mathrm{m} / \mathrm{s}$ \\
\hline $\begin{array}{l}\text { Dependent } \\
\text { variable }\end{array}$ & \multicolumn{2}{|c|}{ Monthly average daily solar radiation (MADSR) } & ( ) $\mathrm{kWh} / \mathrm{m}^{2} /$ day \\
\hline
\end{tabular}




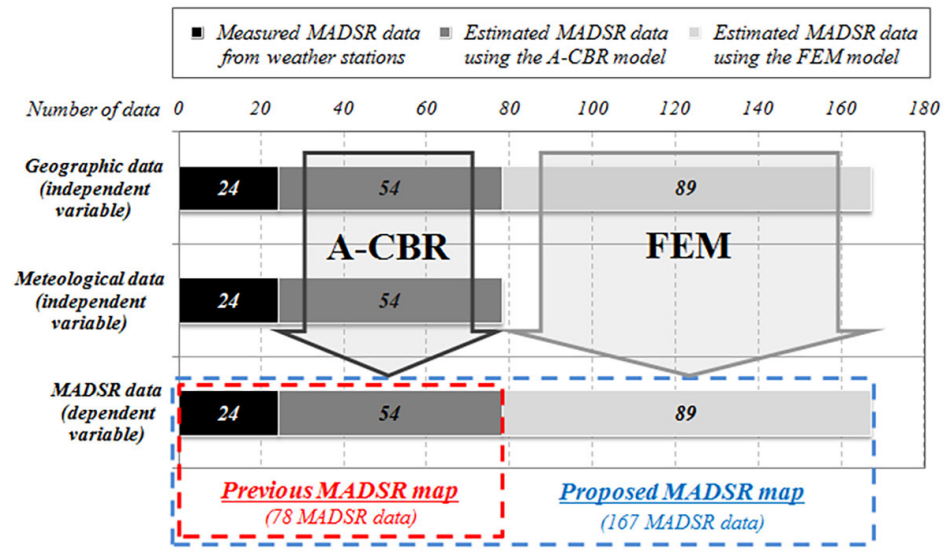

Fig. 2. Data composition

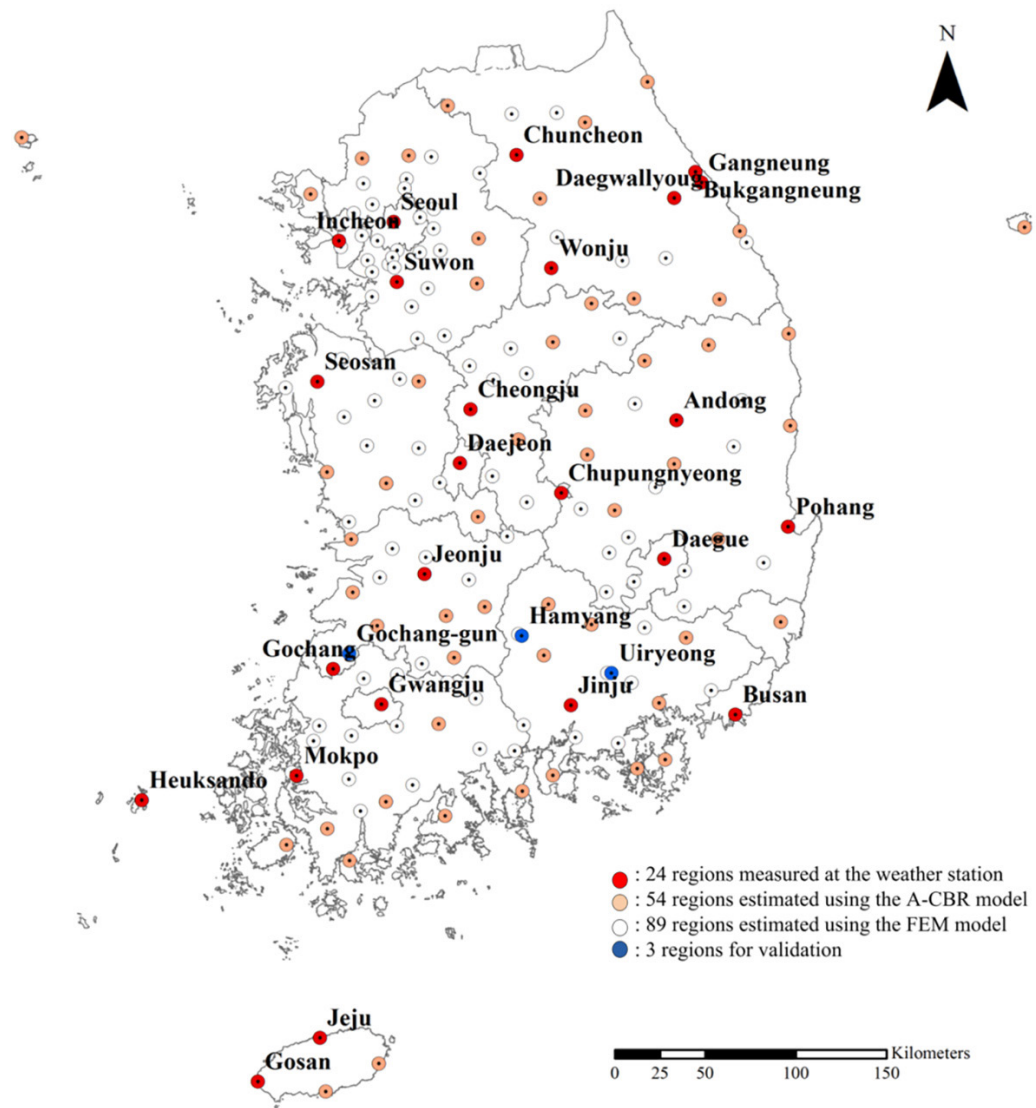

Fig. 3. Geographic locations used for developing the MADSR map 
Meanwhile, this study conducted the validation for South Korea to verify the feasibility of the proposed MADSR map in terms of the estimation accuracy and classification level. To do this, this study selected three locations (i.e., Gochang-gun, Hamyang, and Uiryeong), which were not used in developing the proposed MADSR map. The MADSR data in the three locations were measured from the collaborative meteorological observatory (refer to the blue circle in Fig. 3). In addition, this study used the MAPE to evaluate the estimation accuracy of the A-CBR model, the FEM model, and the proposed MADSR map (refer to Eq. (1)):

$$
M A P E=\sum_{i=1}^{n}\left|\frac{M M_{i}-E M_{i}}{M M_{i}}\right| \times \frac{1}{n} \times 100,
$$

where: $M A P E$ stands for the mean absolute percentage error; $M M$ stands for the measured MADSR; EM stands for the estimated MADSR; and $n$ stands for the number of month.

\subsection{Step 2: Estimation of the MADSR data in the 54 unmeasured locations using the A-CBR model}

Based on the collected meteorological and geographic data, the MADSR data in the 54 unmeasured locations could be estimated using the A-CBR model. The A-CBR model was developed by combining the several data-mining techniques, such as the basic CBR, MRA, and ANN models, with the optimization process using GA. This study aimed to ensure the higher prediction accuracy (i.e., the advantage of the MRA and ANN models) as well as the higher explanatory power (i.e., the advantage of the basic CBR model). In previous studies, the A-CBR model was used to estimate various unknown values, such as electricity consumption, gas energy consumption, construction cost, construction duration, and the optimal size of expressway service area (Hong et al. 2012a, 2012b, 2012c, 2014d, 2015; Jeong et al. 2015; Koo et al. 2010, 2011, 2014d, 2014e; Koo, Hong 2015a, 2017). In particular, Koo et al. (2013) and Lee et al. (2014a) developed the A-CBR model to estimate the MADSR data in the 54 unmeasured locations in South Korea. Similarly, this study developed the A-CBR model to estimate the MADSR data in the 54 unmeasured locations in South Korea, which was used for establishing the finite element mesh that could be finally used for developing the FEM model in the following section.

The A-CBR model could be established in three processes: (i) selection process; (ii) filtering process; and (iii) optimization process. For more detailed information on the three processes, please refer to the study of Koo et al. (2013) (refer to Fig. 4).

- (i) Selection process: The similar cases could be selected using the basic CBR model, in which the meteorological and geographic data would be used as the independent variables. Namely, in implementing the concept of the basic CBR model, the attribute similarity could be calculated using the nearest-neighbor retrieval algorithm, and it would be multiplied by the attribute weight to calculate the case similarity. Finally, depending on the case similarity, the similar cases could be selected (Koo, Hong 2015a, 2017). 


\section{A Process for developing an Advanced Case-Based Reasoning (A-CBR) model}

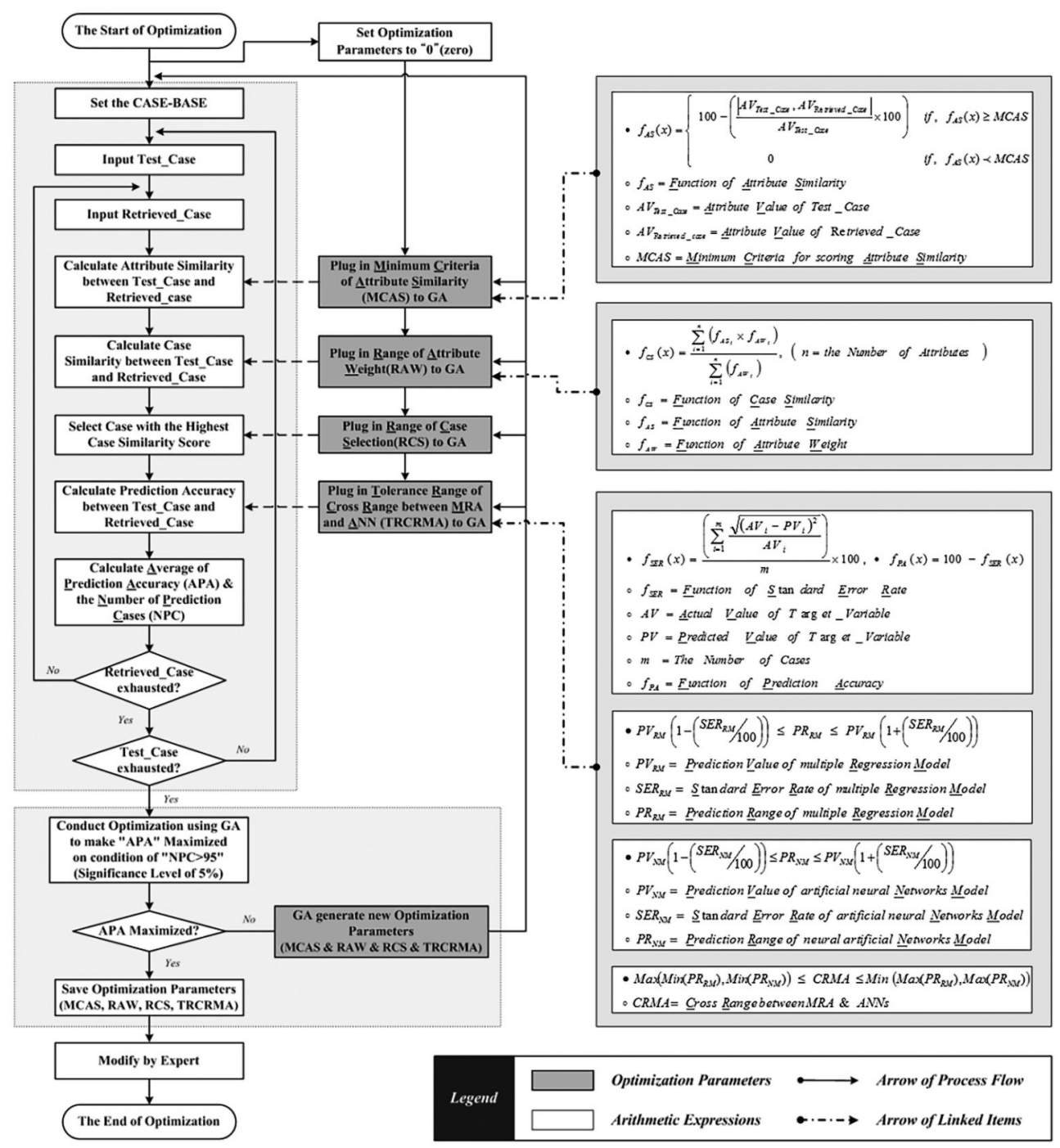

Fig. 4. A process for developing an A-CBR model (refer to Koo et al. (2013))

- (ii) Filtering process: Among the similar cases that were retrieved in the selection process, some similar cases that would be classified as an outlier should be excluded from the entire similar cases. To do this, the filtering range could be established using the estimated values by the MRA and ANN models. First, for the MRA model, the optimal regression equation and regression coefficient could be determined by examining the input variable selection methods (i.e., all possible selection, forward 
selection, backward elimination, and stepwise selection), the adjusted $\mathrm{R}^{2}$, the significant probability (p-value), the multi-collinearity, and the residual analysis (Koo et al. 2010, 2015). This study used the stepwise selection method to determine the optimal MRA model. The detailed statistics of the MRA model by month could be found in SI Table S4 and SI Table S5. Second, for the ANN model, the optimal neural network could be determined by examining the learning methods (i.e., supervised and unsupervised learning), the structural parameters (i.e., the input layer, output layer, and hidden layer), and the training parameters (i.e., step-size (training rate) and momentum) (Jeong et al. 2014; Koo et al. 2010). This study used the multi-layer perception method, in which the combination function and the activation function (i.e., transfer function such as the hyperbolic tangent function). The detailed statistics of the ANN model by month could be found in SI Table S6.

- (iii) Optimization process: GA was used to maximize the estimation accuracy of the A-CBR model. GA defined a group of optimization parameters, where the following four optimization parameters were considered: (a) the minimum criterion for scoring the attribute similarity (MCAS) that was defined as the adjustable parameter within a range of $0-100 \%$ in GA; (b) the range of the attribute weights (RAW) that was defined as the adjustable parameter with a range of $0.00-1.00$ in GA; (c) the range of the case selection (RCS) that was defined as the adjustable parameter with a range of $0-100 \%$ in GA; and (d) the tolerance range of the cross-range between the predicted values of the MRA and ANN models (TRCRMA) that was defined as the adjustable parameter with a range of $0-100 \%$ in GA (Koo et al. 2014d, 2014e).

\subsection{Step 3: Estimation of the MADSR data in the 89 unmeasured locations using the FEM model}

Based on the collected geographic data, the MADSR data in the 89 unmeasured locations could be estimated using the FEM model. The FEM model could solve non-linear problems through the discretization process, in which continuous problems are converted into discrete problems (Casadei, Gabellini 1997; Koo et al. 2014c; Polycarpou 2006; Seo et al. 2015, Stromberg et al. 2012; Unger et al. 2006). Generally, the FEM model could be established in three processes: (i) determination of the finite element; (ii) determination of the shape function; and (iii) development of the interpolation function.

- (i) Determination of the finite element: This is the first step for developing the FEM model (Koo et al. 2014c; Seo et al. 2015; Stromberg et al. 2012; Unger et al. 2006). In this study, the finite element mesh was established based on the 167 locations (i.e., the 24 measured MADSR data from weather stations, the 54 estimated MADSR data using the A-CBR model, and the 89 estimated MADSR data using the FEM model), which would be used to develop the MADSR map (refer to Fig. 3). In particular, the quadrilateral finite elements could be used to estimate the MADSR data in the unmeasured locations. The quadrant could be established based on the target region (refer to the green circle in Fig. 5). Namely, the nearest four locations in the quadrant could be defined as the four nodes of the quadrilateral finite elements. 
- (ii) Determination of the shape function: The shape function could be determined by considering the finite element mesh that would be established in the previous process (i.e., the determination of the finite element). According to Koo et al. (2014c) and Seo et al. (2015), the Lagrangian shape function could be determined to be suitable for estimating the MADSR data in the unmeasured locations. The Lagrangian quadrilateral elements could be expressed as Eq. (2) (i.e., $\xi, \eta, \xi \cdot \eta$, and a constant) by considering the Pascal's triangle (refer to SI Fig. S1), which could be used to define the type of variables (i.e., $\xi$ and $\eta$ ) and functions (i.e., $\varphi(\xi, \eta)$ ). As shown in Figure 5, $\xi$ and $\eta$ could be defined as the latitude (x-axis) and the longitude (y-axis), respectively. Also, $\varphi(\xi, \eta)$ could be defined as the MADSR data in the unmeasured locations that would be estimated using the FEM model.

- (iii) Development of the interpolation function: Based on the Lagrangian shape function, the interpolation function could be established to estimate the MADSR data in the unmeasured locations (refer to Eq. (3)). In this study, the geographic data (i.e., the latitude and longitude) could be converted using the Transverse Mercator 128 coordinate system developed by the National Geographic Institute. Using the latitude ( $\xi$ ) with the range of 100,789 to 660,276 and the longitude $(\eta)$ with the range of 59,041 to 668,232 , the MADSR data in the unmeasured locations could be estimated using the interpolation function. The coefficients $(\alpha 1-\alpha 4)$ in the interpolation function could be determined using the $\xi-\eta$ matrix and the inverse matrix (refer to Eq. (4)).

$$
\varphi(\xi, \eta)=\left(\alpha_{1} \times \xi\right)+\left(\alpha_{2} \times \xi \cdot \eta\right)+\left(\alpha_{3} \times \eta\right)+\alpha_{4}
$$

$$
\left[\begin{array}{cccc}
\xi_{1 \text { st quad. }} & \xi_{1 \text { st quad. }} \cdot \eta_{1 \text { st quad. }} & \eta_{1 \text { st quad. }} & 1 \\
\xi_{2 \text { nd quad. }} & \xi_{2 \text { nd quad. }} \cdot \eta_{2 \text { nd quad. }} & \eta_{2 \text { nd quad. }} & 1 \\
\xi_{3 \text { rd quad. }} & \xi_{3 \text { rd quad. }} \cdot \eta_{3 \text { rd quad. }} & \eta_{3 \text { rd quad. }} & 1 \\
\xi_{4 \text { th quad. }} & \xi_{4 \text { th quad. }} \cdot \eta_{4 \text { th quad. }} & \eta_{4 \text { th quad. }} & 1
\end{array}\right]\left[\begin{array}{c}
\alpha_{1} \\
\alpha_{2} \\
\alpha_{3} \\
\alpha_{4}
\end{array}\right]=\left[\begin{array}{c}
\varphi_{1}\left(\xi_{1 \text { st quad. }} \cdot \eta_{1 \text { st quad. }}\right) \\
\varphi_{2}\left(\xi_{2 \text { nd quad. }} \cdot \eta_{2 \text { nd quad. }}\right) \\
\varphi_{3}\left(\xi_{3 \text { rd quad. }} \cdot \eta_{3 \text { rd quad. }}\right) \\
\varphi_{4}\left(\xi_{4 \text { th quad. }} \cdot \eta_{4 \text { th quad. }}\right)
\end{array}\right]
$$

$$
\left[\begin{array}{l}
\alpha_{1} \\
\alpha_{2} \\
\alpha_{3} \\
\alpha_{4}
\end{array}\right]=\left[\begin{array}{llll}
\xi_{1 \text { st quad. }} & \xi_{1 \text { st quad. }} \cdot \eta_{1 \text { st quad. }} & \eta_{1 \text { st quad. }} & 1 \\
\xi_{2 \text { nd quad. }} & \xi_{2 \text { nd quad. }} \cdot \eta_{2 \text { nd quad. }} & \eta_{2 \text { nd quad. }} & 1 \\
\xi_{3 \text { rd quad. }} & \xi_{3 \text { rd quad. }} \cdot \eta_{3 \text { rd quad. }} & \eta_{3 \text { rd quad. }} & 1 \\
\xi_{\text {th quad. }} & \xi_{4 \text { th quad. }} \cdot \eta_{4 \text { th quad. }} & \eta_{\text {th quad. }} & 1
\end{array}\right]^{-1}\left[\begin{array}{c}
\varphi_{1}\left(\xi_{1 \text { st quad. }} \cdot \eta_{1 \text { st quad. }}\right) \\
\varphi_{2}\left(\xi_{2 \text { nd quad. }} \cdot \eta_{2 \text { nd quad. }}\right) \\
\varphi_{3}\left(\xi_{3 \text { rd quad. }} \cdot \eta_{3 \text { rd quad. }}\right) \\
\varphi_{4}\left(\xi_{4 \text { th quad. }} \cdot \eta_{4 \text { th quad. }}\right)
\end{array}\right],
$$

where: $\varphi$ stands for the MADSR data that were estimated using the FEM model; $\xi$ stands for the latitude; $\eta$ stands for the longitude; $\alpha_{1}-\alpha_{4}$ stand for the coefficient by variable; $1_{s t}$ quad. stands for the first quadrant; $2_{n d}$ quad. stands for the second quadrant; $3_{r d}$ quad. stands for the third quadrant; and $4_{t h}$ quad. stands for the fourth quadrant. 


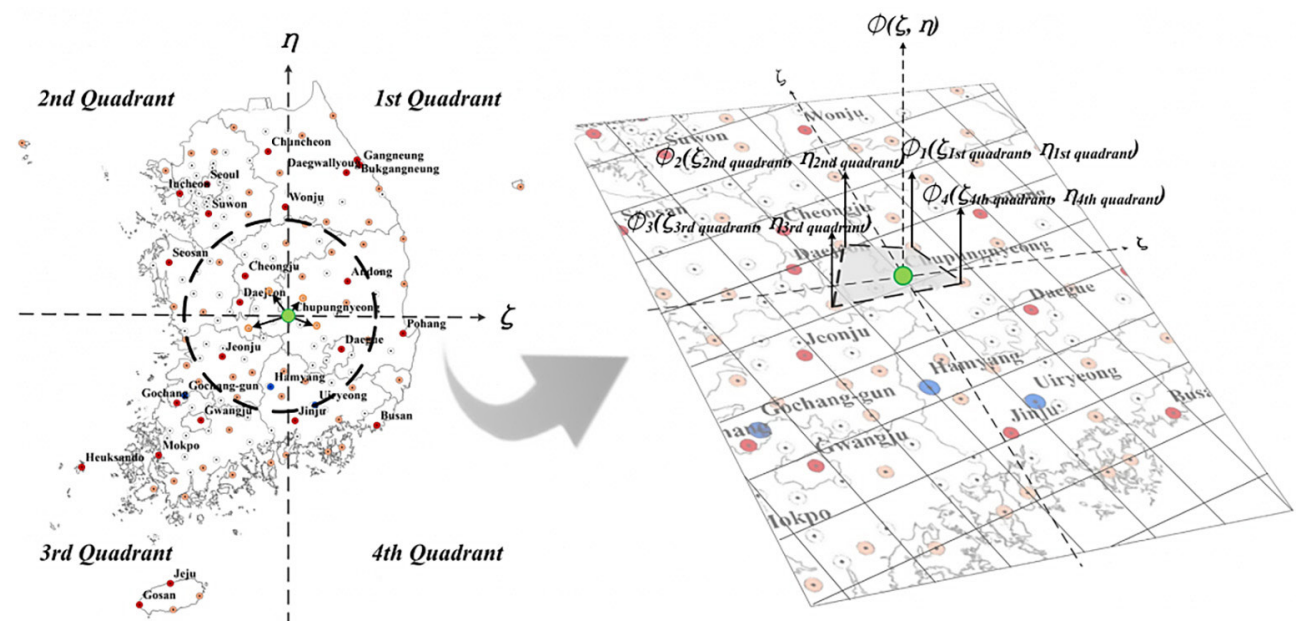

Fig. 5. Concept of the Lagrangian shape function in quadrilateral coordinates

\subsection{Step 4: Development of the MADSR map using the kriging method}

Based on the MADSR data in the 167 locations (i.e., the 24 measured MADSR data from weather stations, the 54 estimated MADSR data using the A-CBR model, and the 89 estimated MADSR data using the FEM model), this study developed the MADSR map using the kriging method, as one of the geostatistical approaches. The spatial correlations could be analyzed using both the aforementioned MADSR data in the 167 locations and the MADSR data that would be estimated using the kriging method (refer to Eq. (5)). To determine the weights assigned to the measured locations (i.e., $\lambda_{i}$ in Eq. (5)), it is required to minimize the error between the aforementioned MADSR data in the 167 locations (i.e., $Z\left(s_{i}\right)$ in Eq. (5)) and the MADSR that would be estimated using the kriging method (i.e., $\hat{Z}\left(s_{0}\right)$ in Eq. (5)). In addition, the MADSR data that would be estimated using the kriging method (i.e., $\hat{Z}\left(s_{0}\right)$ in Eq. (5)) should be unbiased (Bae 2008; Koo et al. 2013; Lee et al. 2014a, 2014b; Rehman, Ghori 2000).

$$
\hat{Z}\left(s_{0}\right)=\sum_{i=1}^{N} \lambda_{i} Z\left(s_{i}\right),
$$

where: $\hat{Z}\left(s_{0}\right)$ stands for the estimated value in the unmeasured region $\left(S_{0}\right) ; Z\left(s_{i}\right)$ stands for the measured value at the measured locations $\left(S_{i}\right) ; N$ stands for the number of measured locations $\left(S_{i}\right)$ around the unmeasured locations $\left(S_{0}\right)$; and $\lambda_{i}$ stands for the weights assigned to the measured locations $\left(S_{i}\right)$.

According to the weight calculation method, the kriging method could be categorized into three types: (i) simple kriging; (ii) ordinary kriging; and (iii) universal kriging (Lee et al. 2014a; Wackernagel 2014):

- (i) Simple kriging: It assumes a known mean. When the error variance is minimized, the weights assigned to the measured locations could be determined (refer to Eq. (6)). As the average value calculated by the estimation equation differs from the average value of the measured data, in general, the simple kriging could not be used. 
- (ii) Ordinary kriging: It assumes an unknown constant mean. Like the simple kriging, when the error variance is minimized, the weights assigned to the measured locations could be determined (refer to Eq. (7)). However, the ordinary kriging could solve the limitation of the simple kriging, which means that the expected value would be unknown. To minimize the average difference between the measured and unmeasured locations, the sum of the weight should be at 1 .

- (iii) Universal kriging: It considers the average value depending on the data distribution in the space. Namely, it is a method that considers both the trends of the data distribution and the residual between the measured and estimated data (refer to Eq. (8)):

$$
\sigma^{2}=E\left[\left(Z\left(s_{0}\right)-\hat{Z}\left(s_{0}\right)\right)^{2}\right]
$$

where: $\sigma^{2}$ stands for the error variance; $E$ stands for the expected value (mean value); $Z\left(s_{0}\right)$ stands for the actual value in the unmeasured locations $\left(S_{0}\right)$; and $\hat{Z}\left(s_{0}\right)$ stands for the estimated value in the unmeasured region $\left(S_{0}\right)$ using simple kriging:

$$
E(Z)-E(\hat{Z})=E\left(Z\left(s_{0}\right)\right)-E\left(\sum_{i=1}^{N} \lambda_{i} Z\left(s_{i}\right)\right), \quad \sum_{i=1}^{N} \lambda_{i}=1,
$$

where: $E(Z)$ stands for the expected value (mean value) of the random field; $E(\hat{Z})$ stands for the expected value (mean value) of the ordinary kriging predictor; $Z\left(s_{0}\right)$ stands for the actual value in the unmeasured locations $\left(S_{0}\right) ; Z\left(s_{i}\right)$ stands for the measured value in the measured locations $\left(S_{i}\right) ; N$ stands for the number of the measured locations $\left(S_{i}\right)$ around the unmeasured locations $\left(S_{0}\right)$; and $\lambda_{i}$ stands for the weights assigned to the measured locations $\left(S_{i}\right)$.

$$
\hat{Z}\left(s_{0}\right)=D\left(s_{i}\right)+R\left(s_{i}\right),
$$

where: $\hat{Z}\left(s_{0}\right)$ stands for the estimated value in the unmeasured region $\left(S_{0}\right)$ using universal kriging; $D\left(s_{i}\right)$ stands for the spatial distribution tendency presented by the measured locations $\left(S_{i}\right)$; and $D\left(s_{i}\right)$ stands for the residual.

According to Lee et al. (2014a), the ordinary kriging method was determined as the most suitable for developing the MADSR map. This study used "ArcMap 10.2" software program, which was developed by the Environmental Systems Research Institute, in order to develop the MADSR map.

\section{Results and discussion}

\subsection{Estimation of the MADSR data in the 54 unmeasured locations using the A-CBR model}

The MADSR data in the 54 unmeasured locations were estimated using the A-CBR model (refer to SI Table S1). To verify the feasibility of the A-CBR model, this study compared the estimation accuracy of the A-CBR model with the other models (i.e., the MRA, ANN, basic CBR models), which have been often used in the previous studies. Figure 6 shows the 
comparison of the estimation accuracy by model, in which the average of estimation accuracy and the standard deviation of the estimation accuracy are provided. Results showed that those of the A-CBR model were determined at $95.11 \%$ and $4.78 \%$, respectively.

- (i) Average of estimation accuracy: It was determined that the A-CBR model was superior to the other models (i.e., the MRA, ANN, and basic CBR models) by $0.29 \%$, $0.21 \%$, and $2.66 \%$, respectively (refer to the dark grey bar chart in Fig. 6).

- (ii) Standard deviation of estimation accuracy: It was determined that the A-CBR model was superior to the other models (i.e., the MRA, ANN, and basic CBR models) by $0.68 \%, 0.72 \%$, and $2.40 \%$, respectively (refer to the light grey bar chart in Fig. 6).

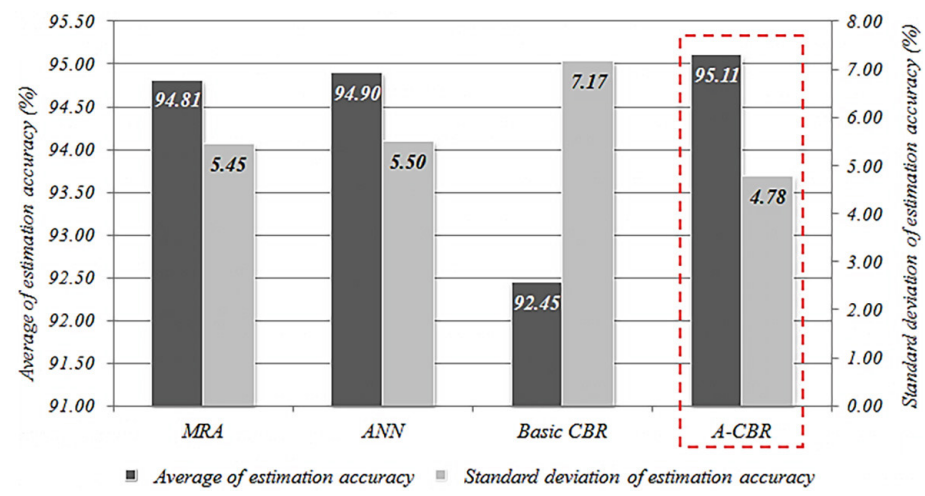

Fig. 6. Comparison of the estimation accuracy by model

As a result, it was determined that the A-CBR model was the most suitable methodology for estimating the MADSR data in the unmeasured locations. The A-CBR model could simultaneously provide the strength of the MRA and ANN models (i.e., excellent estimation accuracy) as well as the merit of the basic CBR model (i.e., the estimation results provided with the retrieved historical cases). Meanwhile, SI Table S7 shows the estimation results of the MADSR data in the 54 unmeasured locations using the A-CBR model.

\subsection{Estimation of the MADSR data in the 89 unmeasured locations using the FEM model}

The MADSR data in the 89 unmeasured locations were estimated using the FEM model (refer to SI Table S2). SI Figure S2 shows the application of the Lagrangian shape function in quadrilateral coordinates. Based on March in Uiryeong as an example, this study established the MADSR estimation process in the unmeasured locations using the FEM model, which could be explained in three processes: (i) determination of the finite element; (ii) determination of the shape function; and (iii) development of the interpolation function.

- (i) Determination of the finite element: Considering the location of Uiryeong, the nearest four locations in the quadrant were found out, and then they were defined as the four nodes of the quadrilateral finite elements. The four nodes of the quadrilateral 
finite elements (i.e., the 1st quadrant, 2nd quadrant, 3rd quadrant, and 4th quadrant) were determined to be Miryang ( $\xi_{1}: 467,710$ and $\left.\eta_{1}: 321,612\right)$, Hapcheon $\left(\xi_{2}: 415,594\right.$ and $\left.\eta_{2}: 329,531\right)$, Jinju ( $\xi_{3}: 403,842$ and $\left.\eta_{3}: 285,013\right)$, and Changwon ( $\xi_{4}: 452,377$ and $\left.\eta_{4}: 285,873\right)$, respectively.

- (ii) Determination of the shape function: This study used the latitude and longitude for the four nodes of the quadrilateral finite elements to establish the Lagrangian shape function. Accordingly, $\varphi(\xi, \eta)$ in the four locations (i.e., Miryang, Hapcheon, Jinju, and Changwon) were determined to be $\varphi_{1}(467,710,321,612)=4.920, \varphi_{2}(415,594$, $329,531)=4.780, \varphi_{3}(403,842,285,013)=5.125$, and $\varphi_{4}(452,377,285,873)=4.780$, respectively.

- (iii) Development of the interpolation function: This study used the $\xi-\eta$ matrix and the inverse matrix to develop the interpolation functions (refer to Eqs (3) and (4)), which were presented as Eqs (9) and (10). As a result, the Uiryeong's MADSR data in March ( $\xi_{\text {Uiryeong: }}: 423,992$ and $\left.\eta_{\text {Uiryeong }}: 302,581\right)$ was estimated at $4.914 \mathrm{kWh} / \mathrm{m}^{2} /$ day (refer to Eqs (11) and (12)).

$$
\begin{aligned}
& {\left[\begin{array}{llll}
467,710 & 467,710 \cdot 321,612 & 321,612 & 1 \\
415,594 & 415,594 \cdot 329,531 & 329,531 & 1 \\
403,842 & 403,842 \cdot 285,013 & 285,013 & 1 \\
452,377 & 452,377 \cdot 285,873 & 285,873 & 1
\end{array}\right]\left[\begin{array}{l}
\alpha_{1} \\
\alpha_{2} \\
\alpha_{3} \\
\alpha_{4}
\end{array}\right]=\left[\begin{array}{c}
4.920 \\
4.780 \\
5.125 \\
4.780
\end{array}\right]} \\
& {\left[\begin{array}{l}
\alpha_{1} \\
\alpha_{2} \\
\alpha_{3} \\
\alpha_{4}
\end{array}\right]=\left[\begin{array}{llll}
467,710 & 467,710 \cdot 321,612 & 321,612 & 1 \\
415,594 & 415,594 \cdot 329,531 & 329,531 & 1 \\
403,842 & 403,842 \cdot 285,013 & 285,013 & 1 \\
452,377 & 452,377 \cdot 285,873 & 285,873 & 1
\end{array}\right]^{-1}\left[\begin{array}{c}
4.920 \\
4.780 \\
5.125 \\
4.780
\end{array}\right]=\left[\begin{array}{c}
-7.69 E-05 \\
2.45 E-10 \\
-1.08 E-04 \\
3.87 E+01
\end{array}\right]} \\
& \varphi(\xi, \eta)=(-7.69 E-05 \times \xi)+(2.45 E-10 \times \xi \cdot \eta)+(-1.08 E-04 \times \eta)+3.87 E+01 ; \\
& \varphi(423,992,302,581)=(-7.69 E-05 \times 423,992)+(2.45 E-10 \times 423,992 \cdot 302,581)= \\
& (-1.08 E-04 \times 302,581)+3.87 E+01=4.914 \text {, }
\end{aligned}
$$

where: $\alpha_{1}-\alpha_{4}$ stand for the coefficient by variable; $\varphi$ stands for the MADSR data that were estimated using the FEM model; $\xi$ stands for the latitude; and $\eta$ stands for the longitude.

Table 2 shows the estimation results of the Uiryeong's MADSR data using the FEM model. Based on the MADSR data in the 78 locations (i.e., the 24 measured MADSR data from weather stations and the 54 estimated MADSR data using the A-CBR model), the Uiryeong's MADSR data were estimated using the FEM model. The estimation accuracy of the FEM model was evaluated using the MAPE (refer to Eq. (1)), resulting in $3.34 \%$.

Based on the aforementioned process, the MADSR data in the 89 unmeasured locations could be estimated using the FEM model. SI Table S8 shows the estimation results of the MADSR data in the 89 unmeasured locations using the FEM model. As a result, the MADSR data in the 167 locations in South Korea were finally established. 
Table 2. Estimation results of the Uiryeong's MADSR data using the FEM model

\begin{tabular}{lccccccccccccc}
\hline \multirow{2}{*}{ Class } & \multicolumn{10}{c}{ Monthly average daily solar radiation $(\mathrm{kWh} / \mathrm{m} 2 /$ day) } \\
\cline { 2 - 15 } & Jan. & Feb. & Mar. & Apr. & May & Jun. & Jul. & Aug. & Sep. & Oct. & Nov. & Dec. & MAPE \\
\hline Actual & 3.26 & 3.16 & 5.05 & 5.54 & 4.89 & 5.00 & 4.62 & 3.69 & 4.36 & 3.73 & 2.36 & 2.71 & \multirow{2}{*}{3.34} \\
\hline Estimated & 2.99 & 3.27 & 4.91 & 5.44 & 4.97 & 4.98 & 4.41 & 3.75 & 4.35 & 3.69 & 2.18 & 2.53 & \\
\hline
\end{tabular}

\subsection{Development of the MADSR map using the kriging method}

Based on the MADSR data in the 167 locations (i.e., the 24 measured MADSR data from weather stations, the 54 estimated MADSR data using the A-CBR model, and the 89 estimated MADSR data using the FEM model), this study developed the MADSR map using the kriging method. Figure 7 shows the proposed MADSR map, which depends on the various seasonal characteristics in South Korea. Since South Korea is located in the northern hemisphere with a mild climate, it has four distinct seasons. Based on the proposed MADSR map, the seasonal distribution of the MADSR data could be summarized as follows.

- (i) Spring: Figure 7 and SI Figure S3 (i.e., spring season from March to May) show that the MADSR has increased from the northeast to the southwest. For example, the MADSR data of April in Jinju, Mokpo, and Gosan in the southern region were illustrated in the red color, which means that the MADSR data in the three regions were higher than those of the other regions. Also, the deviation of the MADSR data in April was determined at $1.82 \mathrm{kWh} / \mathrm{m}^{2} /$ day (with the range of 4.28 to 6.10).

- (ii) Summer: Figure 7 and SI Figure S4 (i.e., summer season from June to August) show that the MADSR data in the southern and eastern regions were higher than those in the other regions. For example, the MADSR data of July in Mokpo, Busan, and Gosan in the southern region were illustrated in the red color, which means that the MADSR data in the three regions were higher than those in the other regions. Also, the deviation of the MADSR data in July was determined at $3.09 \mathrm{kWh} / \mathrm{m}^{2} /$ day (with the range of 3.01 to 6.10), which was the highest deviation of all the seasons.

- (iii) Autumn: Figure 7 and SI Figure S5 (i.e., autumn season from September to November) show that the MADSR data have increased from the northeast to the southwest. For example, the MADSR data of October in Mokpo and Gosan in the southern region were illustrated in the red color, which means that the MADSR data in the two regions were higher than those in the other regions. Also, the deviation of the MADSR data in October was determined at $1.19 \mathrm{kWh} / \mathrm{m}^{2} /$ day (with the range of 3.11 to 4.30), which was the lowest deviation of all the seasons.

- (iv) Winter: Figure 7 and SI Figure S6 (i.e., winter season from December to February) show that the MADSR data has increased from the northwest to the southeast. For example, the MADSR data of January in Jinju, Busan, and Pohang in the southern region were illustrated in the red color, which means that the MADSR data in the three regions were higher than those in the other regions. Also, the deviation of the MADSR data in January was determined at $1.87 \mathrm{kWh} / \mathrm{m}^{2} /$ day (with the range of 1.33 to 3.20$)$. 


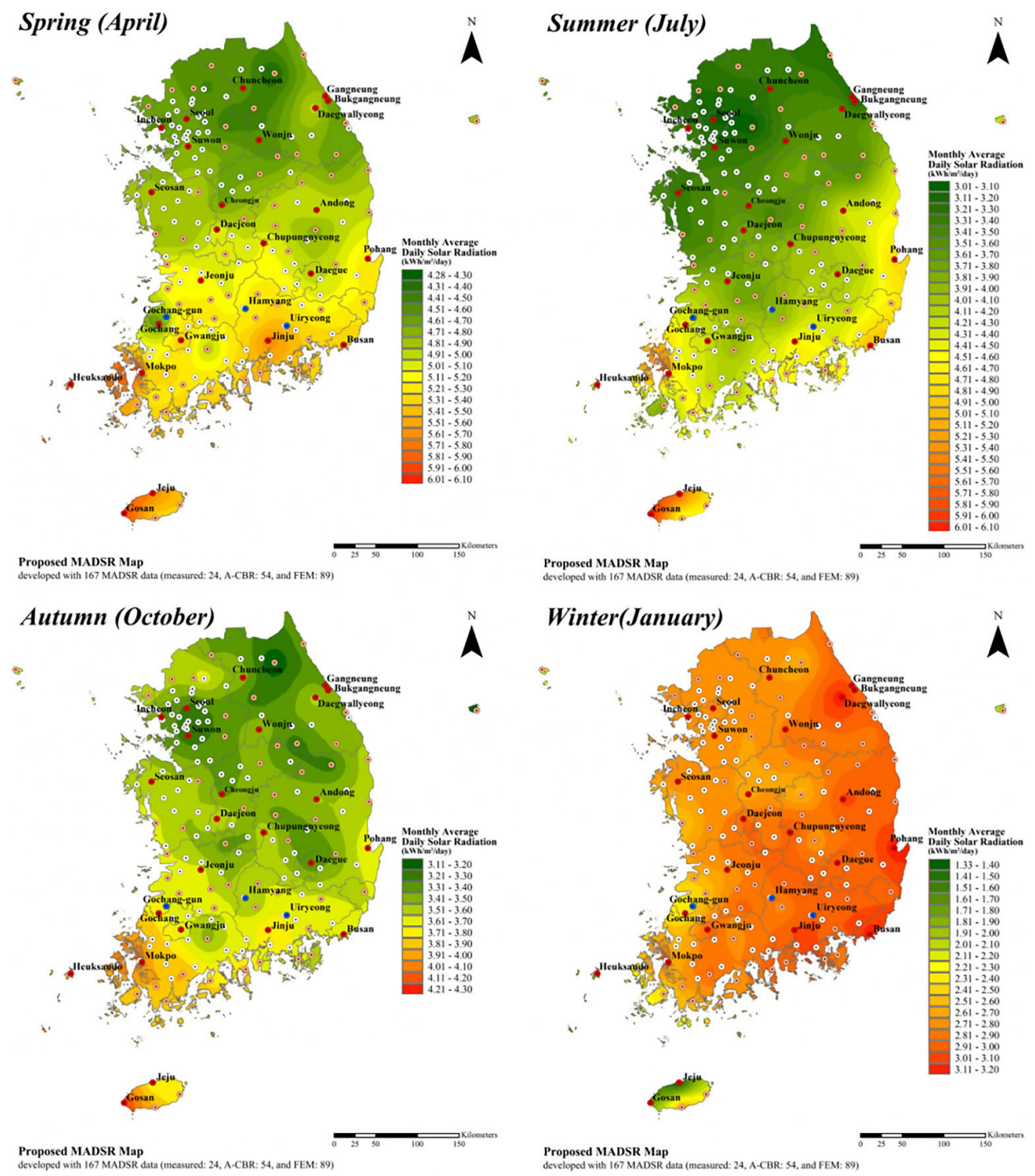

Fig. 7. The proposed MADSR map by season in South Korea

Table 3 shows the comparison of the estimation accuracy between the proposed and previous MADSR maps, in which the 24 measured MADSR data from weather stations were used (refer to SI Table S9 and SI Table S10). First, in terms of the average of estimation accuracy, it was determined that the proposed MADSR map was superior to the previous MADSR maps by $0.57 \%(=1.29-0.72)$. Second, in terms of the standard deviation of estimation accuracy, it was determined that the proposed MADSR map was superior to the previous MADSR maps by $0.36 \%(=1.02-0.66)$. As a result, it could be concluded that the proposed MADSR map was superior to the previous MADSR map, and thus it could be more suitable methodology for estimating the MADSR data in the unmeasured locations. 
Table 3. Comparison of the estimation accuracy between the proposed and previous MADSR maps (24 measured MADSR data from weather stations)

\begin{tabular}{|c|c|c|c|c|c|c|c|c|c|c|c|c|c|c|}
\hline \multirow[b]{2}{*}{ Class } & \multicolumn{14}{|c|}{ MAPE (\%) } \\
\hline & Jan. & Feb. & Mar. & Apr. & May & Jun. & Jul. & Aug. & Sep. & Oct. & Nov. & Dec. & Average & $\begin{array}{l}\text { Standard } \\
\text { deviation }\end{array}$ \\
\hline $\begin{array}{l}\text { Proposed } \\
\text { MADSR } \\
\text { map }\end{array}$ & 0.18 & 2.37 & 0.30 & 0.66 & 0.11 & 0.27 & 0.16 & 0.38 & 0.74 & 0.80 & 1.76 & 0.87 & 0.72 & 0.66 \\
\hline $\begin{array}{l}\text { Previous } \\
\text { MADSR } \\
\text { map }\end{array}$ & 0.28 & 3.03 & 2.41 & 1.24 & 1.58 & 0.07 & 0.40 & 0.89 & 0.39 & 0.66 & 3.14 & 1.45 & 1.29 & 1.02 \\
\hline
\end{tabular}

Note: where: MADSR stands for the monthly average daily solar radiation and MAPE stands for the mean absolute percentage error.

\subsection{Validation for the proposed MADSR map}

This study compared the proposed MADSR map with the previous MADSR map developed in the study of Lee et al. (2014a) in terms of the estimation accuracy and the classification level. To validate the model estimation at region without observation, this study selected the three target locations (i.e., Gochang-gun, Hamyang, and Uiryeong) that were not used in developing the proposed MADSR map.

The proposed MADSR map was developed using the MADSR data from the 167 locations (i.e., the 24 measured MADSR data from weather stations, the 54 estimated MADSR data using the A-CBR model, and the 89 estimated MADSR data using the FEM model). And, the previous MADSR map was developed using the MADSR data from the 78 locations (i.e., the 24 measured MADSR data from weather stations and the 54 estimated MADSR data using the A-CBR model).

\subsubsection{Estimation accuracy of the proposed MADSR map}

The estimation accuracy of the proposed MADSR map was evaluated for the three target locations (i.e., Gochang-gun, Hamyang, and Uiryeong). The MAPE was used to evaluate the estimation accuracy of the proposed MADSR map (refer to Eq. (1)). Generally, because the MAPE does not depend on the scale of the variable, it could be used as an absolute index for comparing the estimation results by model.

Table 4 shows the estimation results of the MADSR data using the proposed and previous MADSR maps. In terms of the MAPE, it was determined that the proposed MADSR map was superior to the previous MADSR map. That is, compared to the previous MADSR map, when using the proposed MADSR map, the estimation accuracy for the three target locations (i.e., Gochang-gun, Hamyang, and Uiryeong) have improved at $0.73 \%(=6.53-$ $5.80), 0.27 \%(=4.88-4.61)$, and $0.07 \%(=3.36-3.29)$, respectively.

\subsubsection{Classification level of the proposed MADSR map}

The classification level of the proposed MADSR map was evaluated for the three target locations (i.e., Gochang-gun, Hamyang, and Uiryeong). In particular, a detailed analysis was conducted for the MADSR data of March in the three target locations. 
Table 4. Comparison of the estimation accuracy of the proposed and previous MADSR maps (three target locations for validation)

\begin{tabular}{|c|c|c|c|c|c|c|c|c|c|c|c|c|c|c|}
\hline \multirow{2}{*}{ Region } & \multirow{2}{*}{ Class } & \multicolumn{12}{|c|}{ Monthly average daily solar radiation (kWh/m2/day) } & \multirow{2}{*}{$\begin{array}{c}\text { MAPE } \\
(\%)\end{array}$} \\
\hline & & Jan. & Feb. & Mar. & Apr. & May & Jun. & Jul. & Aug. & Sep. & Oct. & Nov. & Dec. & \\
\hline \multirow{3}{*}{ 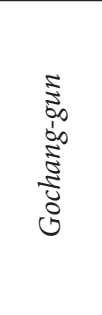 } & $\begin{array}{l}\text { Actual } \\
\text { value }\end{array}$ & 2.02 & 2.62 & 4.04 & 4.34 & 4.61 & 5.08 & 4.26 & 3.68 & 4.57 & 3.73 & 2.22 & 1.99 & - \\
\hline & $\begin{array}{l}\text { Proposed } \\
\text { MADSR } \\
\text { map }\end{array}$ & 2.42 & 2.91 & 4.43 & 4.86 & 4.82 & 5.13 & 4.32 & 3.61 & 4.55 & 3.69 & 2.13 & 1.94 & 5.80 \\
\hline & $\begin{array}{l}\text { Previous } \\
\text { MADSR } \\
\text { map }\end{array}$ & 2.41 & 3.04 & 4.59 & 4.83 & 4.87 & 5.14 & 4.32 & 3.61 & 4.55 & 3.70 & 2.13 & 1.94 & 6.53 \\
\hline \multirow{3}{*}{ 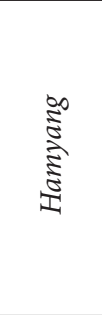 } & $\begin{array}{l}\text { Actual } \\
\text { value }\end{array}$ & 3.05 & 3.29 & 5.14 & 5.41 & 5.31 & 5.32 & 4.07 & 3.61 & 4.35 & 3.72 & 2.33 & 2.42 & - \\
\hline & $\begin{array}{l}\text { Proposed } \\
\text { MADSR } \\
\text { map }\end{array}$ & 2.84 & 3.25 & 4.89 & 5.22 & 5.17 & 5.06 & 3.91 & 3.61 & 4.12 & 3.56 & 2.13 & 2.19 & 4.61 \\
\hline & $\begin{array}{l}\text { Previous } \\
\text { MADSR } \\
\text { map }\end{array}$ & 2.84 & 3.25 & 4.87 & 5.20 & 5.15 & 5.06 & 3.87 & 3.60 & 4.12 & 3.55 & 2.13 & 2.17 & 4.88 \\
\hline \multirow{3}{*}{ 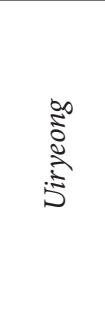 } & $\begin{array}{l}\text { Actual } \\
\text { value }\end{array}$ & 3.26 & 3.16 & 5.05 & 5.54 & 4.89 & 5.00 & 4.62 & 3.69 & 4.36 & 3.73 & 2.36 & 2.71 & - \\
\hline & $\begin{array}{l}\text { Proposed } \\
\text { MADSR } \\
\text { map }\end{array}$ & 2.99 & 3.27 & 4.91 & 5.44 & 4.97 & 4.99 & 4.41 & 3.75 & 4.35 & 3.69 & 2.19 & 2.53 & 3.29 \\
\hline & $\begin{array}{l}\text { Previous } \\
\text { MADSR } \\
\text { map }\end{array}$ & 2.98 & 3.26 & 4.90 & 5.45 & 4.98 & 5.00 & 4.39 & 3.73 & 4.35 & 3.70 & 2.17 & 2.52 & 3.36 \\
\hline
\end{tabular}

Note: where: MADSR stands for the monthly average daily solar radiation and MAPE stands for the mean absolute percentage error.

Figure 8 shows the classification level of the proposed and previous MADSR maps, resulting that the classification levels were determined to be 17 classes and 10 classes, respectively. As shown in the three target locations (i.e., Gochang-gun, Hamyang, and Uiryeong), the classification levels in each region have improved from four classes (4.55-4.81) to 10 classes (4.19-5.01), from two classes (4.83-4.90) to three classes (4.83-5.01), and from two classes (4.85-4.95) to five classes (4.79-5.12), respectively. This is because while the previous MADSR map was developed using the MADSR data from the 78 locations, the proposed MADSR map was developed using the MADSR data from the 167 locations. As a result, in terms of the classification level, it was determined that the proposed MADSR map was superior to the previous MADSR map. 


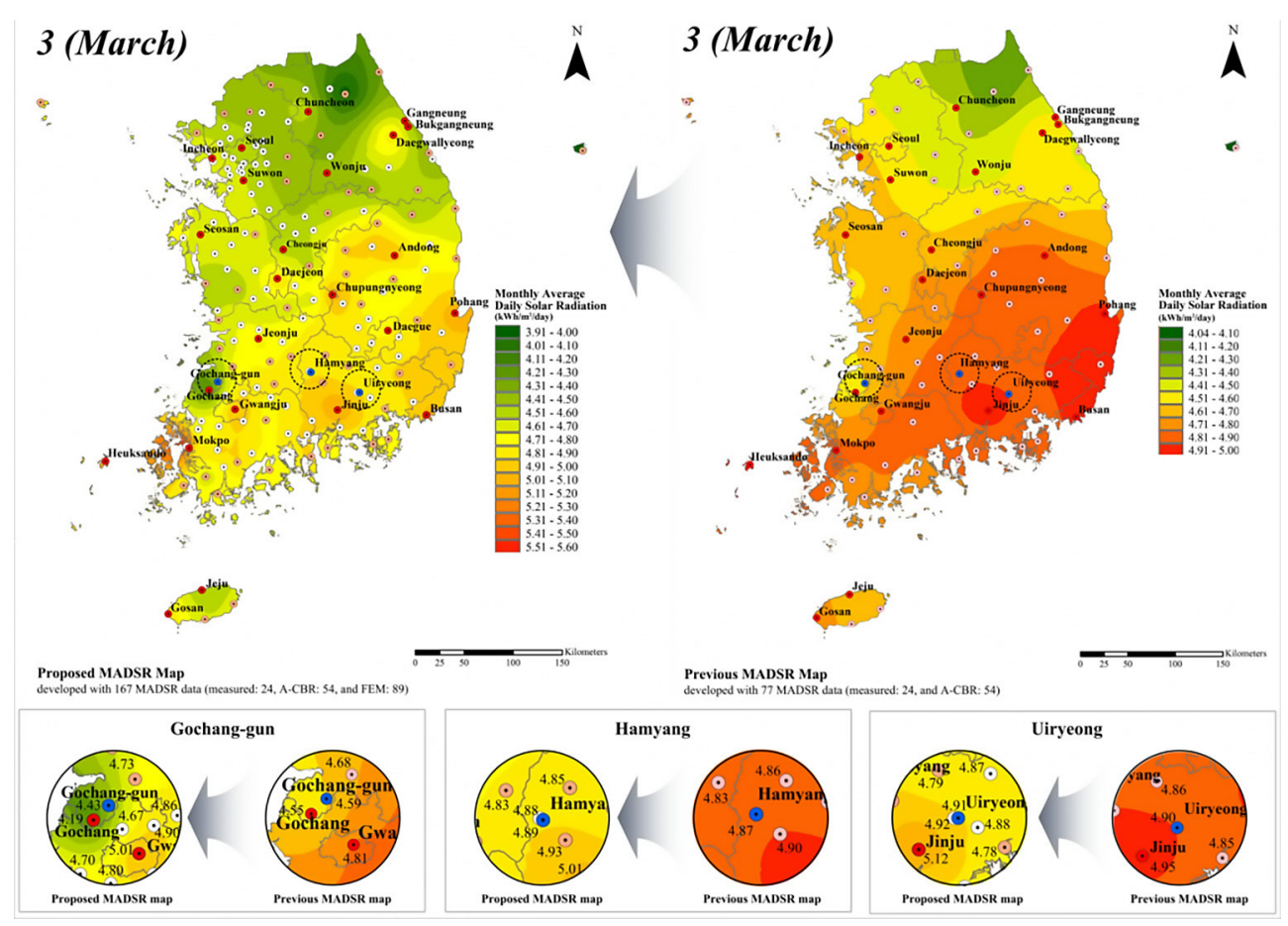

Fig. 8. Classification level of the proposed and previous MADSR maps (March in South Korea)

\section{Conclusions}

The MADSR data need to be accurately measured or estimated in the early phases of projects so that the effectiveness of the PV system could be maximized. Based on these MADSR data, an accurate MADSR map could be developed, which can make it possible to make an intuitive decision for location. Towards this end, this study aimed to develop an MADSR map with improved estimation accuracy using the A-CBR, FEM, and kriging method. This study was conducted in four steps: (i) step 1: data collection; (ii) step 2: estimation of the MADSR data in the 54 unmeasured locations using the A-CBR model; (iii) step 3: estimation of the MADSR data in the 89 unmeasured locations using the FEM model; and (iv) step 4: development of the MADSR map using the kriging method. The main findings could be summarized as follows:

- (i) The study used the A-CBR model to estimate the MADSR data in the 54 unmeasured locations by considering the meteorological data collected from weather stations (i.e., the monthly average temperature, monthly average relative humidity, etc.) and the corresponding geographic data (i.e., the latitude and longitude). However, as it is too expensive to measure the actual MADSR data using the remote sensors, the actual MADSR data cannot be measured in all the sites. In South Korea, which was selected for the validation in this study, the MADSR data were actually collected in the limited locations of the 24 weather stations. To expand the number of the MADSR 
data that could be used for developing the MADSR map, this study developed the FEM model to estimate the MADSR data in the unmeasured locations.

- (ii) This study developed the FEM model to estimate the MADSR data in the 89 unmeasured locations by considering the only geographic data (i.e., the latitude and longitude). As a result, based on the 167 MADSR data (i.e., the 24 measured MADSR data from weather stations, the 54 estimated MADSR data using the A-CBR model, and the 89 estimated MADSR data using the FEM model), this study developed the MADSR map.

- (iii) This study analyzed the estimation accuracy to verify the feasibility of the proposed MADSR map, which was conducted in two ways: (a) for the 24 measured MADSR data from weather stations that were used in developing the proposed MADSR map, it was determined that the proposed MADSR map was superior to the previous MADSR maps by $0.57 \%$ (=1.29-0.72); and (b) for the three target locations (i.e., Gochang-gun, Hamyang, and Uiryeong) that were not used in developing the proposed MADSR map by $0.73 \%(=6.53-5.80), 0.27 \%(=4.88-4.61)$, and $0.07 \%$ (= 3.36-3.29), respectively. In conclusion, it was determined that the proposed MADSR map was superior to the previous MADSR map in terms of the estimation accuracy and the classification level.

The proposed MADSR map could help final decision-makers to evaluate and maximize the effectiveness of the PV system in the early phases of projects by estimating the MADSR data in the unmeasured locations. In addition, the estimation results could be used to determine the optimal location for the installation of the PV system. In particular, it is expected to reduce the cost of measuring the actual MADSR data using the remote sensors. Meanwhile, the research framework proposed in this study could be extended to any other country or sector in the global environment. To do this, it is necessary to collect their own data on the geographic data and meteorological data, which could be collected from the government agency such as the meteorological administration.

\section{Funding}

This work was supported by the National Research Foundation of Korea (NRF) grant funded by the Korea government (MSIP; Ministry of Science, ICT \& Future Planning) (NRF-2015R1A2A1A05001657).

\section{References}

Al-Alawi, S. M.; Al-Hinai, H. A. 1998. An ANN-based approach for predicting global radiation in locations with no direct measurement instrumentation, Renew Energy 14(1-4): 199-204. https://doi.org/10.1016/S0960-1481(98)00068-8

Alsamamra, H.; Ruiz-Arias, J. A.; Pozo-Vázquez, D.; Tovar-Pescador, J. 2009. A comparative study of ordinary and residual kriging techniques for mapping global solar radiation over southern Spain, Agricultural and Forest Meteorology 149(8): 1343-1357. https://doi.org/10.1016/j.agrformet.2009.03.005 
Ashhab, M. S. S. 2008. Optimization and modeling of a photovoltaic solar integrated system by neural networks, Energy Conversion and Management 49(11): 3349-3355.

https://doi.org/10.1016/j.enconman.2007.10.036

Badescu, V. 1999. Correlations to estimate monthly mean daily solar global irradiation: application to Romania, Energy 24(10): 883-893. https://doi.org/10.1016/S0360-5442(99)00027-4

Bae, M. S. 2008. A runoff analysis by kriging method for the Nam River dam basin: Doctoral thesis. Gyeongsang National University, South Korea.

Behrang, M. A.; Assareh, E.; Ghanbarzadeh, A.; Noghrehabadi, A. R. 2010. The potential of different artificial neural network (ANN) techniques in daily global solar radiation modeling based on meteorological data, Solar Energy 84(8): 1468-1480. https://doi.org/10.1016/j.solener.2010.05.009

Caglayan, N.; Ertekin, C.; Evrendilek, F. 2014. Spatial viability analysis of grid-connected photovoltaic power systems for Turkey, International Journal of Electrical Power and Energy Systems 56: 270-278. https://doi.org/10.1016/j.ijepes.2013.11.019

Cano, D.; Monget, J. M.; Albuisson, M.; Guillard, H.; Regas, N.; Wald, L. 1986. A method for the determination of the global solar radiation from meteorological satellite data, Solar Energy 37(1): 31-39. http://www.sciencedirect.com/science/article/pii/0038092X86901040

Casadei, F.; Gabellini, E. 1997. Implementation of a 3D coupled spectral element/finite element solver for wave propagation and soil-structure interaction simulations. Italy, European Commission.

Chegaar, M.; Chibani, A. 2001. Global solar radiation estimation in Algeria, Energy Conversion and Management 42(8): 967-973. https://doi.org/10.1016/S0196-8904(00)00105-9

Cogliani, E.; Ricchiazzi, P.; Maccari, A. 2008. Generation of operational maps of global solar irradiation on horizontal plan and of direct normal irradiation from Meteosat imagery by using SOLARMET, Solar Energy 82(6): 556-562. https://doi.org/10.1016/j.solener.2007.11.002

Coskun, C.; Oktay, Z.; Dincer, I. 2001. Estimation of monthly solar radiation distribution for solar energy system analysis, Energy 36(2): 1319-1323. https://doi.org/10.1016/j.energy.2010.11.009

Gastli, A.; Charabi, Y. 2010. Solar electricity prospects in Oman using GIS-based solar radiation maps, Renewable and Sustainable Energy Reviews 14(2): 790-797. https://doi.org/10.1016/j.rser.2009.08.018

Geraldi, E.; Romano, F.; Ricciardelli, E. 2012. An advanced model for the estimation of the surface solar irradiance under all atmospheric conditions using MSG/SEVIRI data, IEEE Transactions on Geoscience and Remote Sensing 50(8): 2934-2953. https://doi.org/10.1109/TGRS.2011.2178855

Hammer, A.; Heinemann, D.; Hoyer, C.; Kuhlemann, R.; Lorenz, E.; Müller, R.; Beyer, H. G. 2003. Solar energy assessment using remote sensing technologies, Remote Sensing of Environment 86(3): 423-432. https://doi.org/10.1016/S0034-4257(03)00083-X

Holt, M.; Campbell, R. J.; Nikitin, M. B. 2012. Fukushima nuclear disaster. Congressional Research Service (CRS).

Hong, T.; Koo, C.; Jeong, K. 2012a. A decision support model for reducing electric energy consumption in elementary school facilities, Applied Energy 95: 253-266.

https://doi.org/10.1016/j.apenergy.2012.02.052

Hong, T.; Koo, C.; Kim, D.; Lee, M.; Kim, J. 2015. An estimation methodology for the dynamic operational rating of a new residential building using the advanced case-based reasoning and stochastic approaches, Applied Energy 150(15 July): 308-322. https://doi.org/10.1016/j.apenergy.2015.04.036

Hong, T.; Koo, C.; Kim, H. 2012c. A decision support model for improving a multi-family housing complex based on $\mathrm{CO} 2$ emission from electricity consumption, Journal of Environmental Management 112: 67-78. https://doi.org/10.1016/j.jenvman.2012.06.046

Hong, T.; Koo, C.; Kim, H.; Park, H. S. 2014c. Decision support model for establishing the optimal energy retrofit strategy for existing multi-family housing complexes, Energy Policy 66: 157-169. https://doi.org/10.1016/j.enpol.2013.10.057 
Hong, T.; Koo, C.; Kwak, T.; Park, H.S. 2014b. An economic and environmental assessment for selecting the optimum new renewable energy system for educational facility, Renewable and Sustainable Energy Reviews 29: 286-300. https://doi.org/10.1016/j.rser.2013.08.061

Hong, T.; Koo, C.; Lee, M. 2013. Estimating the loss ratio of solar photovoltaic electricity generation through stochastic analysis, Journal of Construction Engineering and Project Management 3(3): 23-34. http://www.jcepm.org/english/viewtopic.php?t=437

Hong, T.; Koo, C.; Lee, S. 2014d. Benchmarks as a tool for free allocation through comparison with similar projects: focused on multi-family housing complex, Applied Energy 114: 663-675. https://doi.org/10.1016/j.apenergy.2013.10.035

Hong, T.; Koo, C.; Park, J.; Park, H. S. 2014a. A GIS (geographic information system)-based optimization model for estimating the electricity generation of the rooftop PV (photovoltaic) system, Energy 65: 190-199. https://doi.org/10.1016/j.energy.2013.11.082

Hong, T.; Koo, C.; Park, S. 2012b. A decision support model for improving a multi-family housing complex based on $\mathrm{CO} 2$ emission from gas energy consumption, Building and Environment 52: 142-151. https://doi.org/10.1016/j.buildenv.2012.01.001

Janjai, S. 2010. A method for estimating direct normal solar irradiation from satellite data for a tropical environment, Solar Energy 84(9): 1685-1695. https://doi.org/10.1016/j.solener.2010.05.017

Jeong, K.; Ji, C.; Koo, C.; Hong, T.; Park, H. S. 2015. A model for predicting the environmental impacts of educational facilities in the project planning phase, Journal of Cleaner Production 107: 538-549. https://doi.org/10.1016/j.jclepro.2014.01.027

Jeong, K.; Koo, C.; Hong, T.; Park, H. 2014. An estimation model for determining the annual energy cost budget in educational facilities using SARIMA (seasonal autoregressive integrated moving average) and ANN (artificial neural network), Energy 71: 71-79.

https://doi.org/10.1016/j.energy.2014.04.027

Koo, C.; Hong, T. 2015a. A dynamic energy performance curve for evaluating the historical trends in the energy performance of existing buildings using a simplified case-based reasoning approach, Energy and Buildings 92: 338-350. https://doi.org/10.1016/j.enbuild.2015.02.004

Koo, C.; Hong, T. 2017. Development of a dynamic incentive and penalty program for improving the energy performance of existing buildings, Technological and Economic Development of Economy (in press).

Koo, C.; Hong, T.; Hyun, C. 2011. The development of a construction cost prediction model with improved prediction capacity using the advanced CBR approach, Expert Systems with Applications 38(7): 8597-8606. https://doi.org/10.1016/j.eswa.2011.01.063

Koo, C.; Hong, T.; Hyun, C.; Koo, K. 2010. A CBR-based hybrid model for predicting a construction duration and cost based on project characteristics in multi-family housing projects, Canadian Journal of Civil Engineering 37(5): 739-752. https://doi.org/10.1139/L10-007

Koo, C.; Hong, T.; Kim, J. 2014e. A decision support system for determining the optimal size of a new expressway service area: focused on the profitability, Decision Support Systems 67: 9-20. https://doi.org/10.1016/j.dss.2014.07.005

Koo, C.; Hong, T.; Kim, J.; Kim, H. 2015. An integrated multi-objective optimization model for establishing the low-carbon scenario 2020 to achieve the national carbon emissions reduction target for residential buildings, Renewable and Sustainable Energy Reviews 49: 410-425. https://doi.org/10.1016/j.rser.2015.04.120

Koo, C.; Hong, T.; Lee, M.; Park, H. S. 2013. Estimation of the monthly average daily solar radiation using geographic information system and advanced case-based reasoning, Environmental Science and Technology 47(9): 4829-4839. https://doi.org/10.1021/es303774a

Koo, C.; Hong, T.; Lee, M.; Park, H. S. 2014d. Development of a new energy efficiency rating system for existing residential buildings, Energy Policy 68: 218-231. https://doi.org/10.1016/j.enpol.2013.12.068 
Koo, C.; Hong, T.; Park, H. S.; Yun, G. 2014b. Framework for the analysis of the potential of the rooftop photovoltaic system to achieve the net-zero energy solar buildings, Progress in Photovoltaics: Research and Applications 22(4): 462-478. https://doi.org/10.1002/pip.2448

Koo, C.; Kim, H.; Hong, T. 2014a. Framework for the analysis of the low-carbon scenario 2020 to achieve the national carbon Emissions reduction target: focused on educational facilities, Energy Policy 73: 356-367. https://doi.org/10.1016/j.enpol.2014.05.009

Koo, C.; Park, S.; Hong, T.; Park, H. S. 2014c. An estimation model for the heating and cooling demand of a residential building with a different envelope design using the finite element method, Applied Energy 115: 205-215. https://doi.org/10.1016/j.apenergy.2013.11.014

Korea Energy Management Corporation (KEMC). 2012. New and renewable energy white paper. Gyeonggi-do, South Korea, KEMC.

Lee, M.; Koo, C.; Hong, T.; Park, H. S. 2014a. Framework for the mapping of the monthly average daily solar radiation using an advanced case-based reasoning and a geostatistical technique, Environmental Science and Technology 48(8): 4604-4612. https://doi.org/10.1021/es405293u

Lee, S. W.; Lee, S. W.; Lee, S. Y.; Hong, W. H. 2014b. A study on estimation of the greenhouse gas emission from the road transportation infrastructure using the geostatistical analysis - a case of the Daegu, Journal of Korea Spatial Information Society 22(1): 9-17. https://doi.org/10.12672/ksis.2014.22.1.009

Lueken, C.; Cohen, G. E.; Apt, J. 2012. Costs of solar and wind power variability for reducing CO2 emissions, Environmental Science and Technology 46(17): 9761-9767. https://doi.org/10.1021/es204392a

Mohandes, M.; Rehman, S.; Halawani, T. O. 1998. Estimation of global solar radiation using artificial neural networks, Renewable Energy 14(1-4): 179-184. https://doi.org/10.1016/S0960-1481(98)00065-2

Mubiru, J.; Banda, E. J . K. B. 2008. Estimation of monthly average daily global solar irradiation using artificial neural networks, Solar Energy 82(2): 181-187. https://doi.org/10.1016/j.solener.2007.06.003

Polycarpou, A.C. 2006. Introduction to the finite element method in electromagnetics. U.S., Morgan \& Claypool Publishers.

Ramedani, Z.; Omid, M.; Keyhani, A.; Shamshirband, S.; Khoshnevisan, B. 2014. Potential of radial basis function based support vector regression for global solar radiation prediction, Renewable and Sustainable Energy Reviews 39: 1005-1011. https://doi.org/10.1016/j.rser.2014.07.108

Reddy, K. S.; Ranjan, M. 2003. Solar resource estimation using artificial neural networks and comparison with other correlation models, Energy Conversion and Management 44(15): 2519-2530. https://doi.org/10.1016/S0196-8904(03)00009-8

Rehman, S.; Ghori, S. G. 2000. Spatial estimation of global solar radiation using geostatistics, Renewable Energy 21(3-4): 583-605. https://doi.org/10.1016/S0960-1481(00)00078-1

Saffaripour, M. H.; Mehrabian, M. A.; Bazargan, H. 2013. Predicting solar radiation fluxes for solar energy system applications, International Journal of Environmental Science and Technology 10(4): 761-768. https://doi.org/10.1007/s13762-013-0179-2

Şahin, M.; Kaya, Y.; Uyar, M. 2013. Comparison of ANN and MLR models for estimating solar radiation in Turkey using NOAA/AVHRR data, Advances in Space Research 51(5): 891-904. https://doi.org/10.1016/j.asr.2012.10.010

Seo, D.; Koo, C.; Hong, T. 2015. A Lagrangian finite element model for estimating the heating and cooling demand of a residential building with a different envelope design, Applied Energy 142: 66-79. https://doi.org/10.1016/j.apenergy.2014.12.051

Sözen, A.; Arcaklıoğlu, E.; Özalp, M.; Çağlar, N. 2005. Forecasting based on neural network approach of solar potential in Turkey, Renewable Energy 30(7): 1075-1090.

https://doi.org/10.1016/j.renene.2004.09.020. 
Stromberg, L. L.; Beghini, A.; Baker, W. F.; Paulino, G. H. 2012. Topology optimization for braced frames: combining continuum and beam/column elements, Engineering Structures 37: 106-124. https://doi.org/10.1016/j.engstruct.2011.12.034.

Šúri, M.; Hofierka, J. 2004. A new GIS-based solar radiation model and its application to photovoltaic assessments, TransActions in GIS 8(2): 175-190. https://doi.org/10.1111/j.1467-9671.2004.00174.x

Unger, J.; Teughels, A.; De Roeck, G. 2006. System identification and damage detection of a prestressed concrete beam, Journal of Structural Engineering 132(11): 1691-1698. https://doi.org/10.1061/(ASCE)0733-9445(2006)132:11(1691)

Wackernagel, H. 2014. Multivariate geostatistics: an introduction with applications. Germany, Springer.

Choongwan KOO. He is an Assistant Professor in the Department of Building Services Engineering at The Hong Kong Polytechnic University and also a Research Professor in the Department of Architectural Engineering at Yonsei University. His primary research areas include sustainable facility engineering \& management, real-time urban energy demand-side management, occupant behavior and energy efficiency, urban sustainability policy, renewable \& sustainable energy supply-side management, monitoring and diagnostics, predictive and prescriptive analytics, data visualization, data mining \& simulation techniques, sensor and actuator.

Taehoon HONG. He is a Professor in the Department of Architectural Engineering at Yonsei University. $\mathrm{He}$ is an Associate Editor in the Journal of Management in Engineering, ASCE. His main research areas include sustainable construction management system, building energy efficiency, solar photovoltaics, life cycle cost analysis, life cycle assessment, construction productivity, infrastructure management, facility management, and construction project cost control.

Kwangbok JEONG. He is a graduate Research Assistant and $\mathrm{PhD}$ candidate at the Department of Architectural Engineering at Yonsei University. His primary research areas include sustainable construction management, life cycle cost, life cycle assessment, educational facility, geographical information system, and solar photovoltaic.

Jimin KIM. He is a post-doctoral fellow at the Department of Architectural Engineering at Yonsei University. His primary research areas include sustainable construction management, life cycle assessment, and construction project environmental impact control. 